\title{
Good Conversations: An Enhanced Model To Teach Business Ethics
}

\author{
Grace S. Thomson, Nevada State College, USA
}

\begin{abstract}
Business practices are a constant matter of discussion by ethical theorists concerned with the conflicts between profitability and justice (Cherry, Lee, \& Chien, 2003). Business decisions are complex and hence likely to be compromised by low-quality or questionable strategies (Carpenter \& Sanders, 2008). The line between misbehavior and legal violations is sometimes crossed because individuals (leaders) are not fully aware of the biases in their judgment (Carpenter \& Sanders, 2008). Business schools play an important role in the preparation of learners in ethics and responsible citizenship. Ethical decision-making models may be used to generate both strong justification and relevant application of rules and principles to an ethical issue, developing alternate ways of thinking (Beschorner, 2006). The use of the Integrative Model of Ethical Decision-Making in an upper-division management course at a public baccalaureate college in Southern Nevada increased students' awareness about ethical issues, provided a framework for logical and moral reasoning, and enabled students to apply deontological and teleological evaluations in ethical judgments. Students acknowledged "good conversations" as a necessary step in ethical decision-making, increased their ethical assessment skills, and engaged in dialogical reasoning. Ethical-decision making models assist in developing better curricula, improving faculty performance, and preparing students with high levels of critical thinking and problem-solving skills.
\end{abstract}

Keywords: business ethics; dialogical reasoning; good conversations; moral reasoning; critical thinking; ethical decision-making; public baccalaureate colleges; higher education

\section{INTRODUCTION}

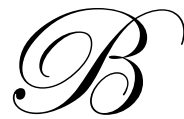

usiness practices are a constant matter of discussion by ethical theorists concerned with the conflicts between profitability and justice (Cherry, Lee, \& Chien, 2003). Business decisions are complex and hence likely to be compromised by low-quality or questionable strategies (Carpenter \& Sanders, 2008). In the analysis of business ethics it is essential to consider that firms face challenges in the market and in the non-market environment (Baron, 2006). The market environment is characterized by rules and contracts that engage firms, suppliers and customers in a cycle of economic activity. The nonmarket environment comprise interactions between the firm and other constituencies, government entities, and interest groups, that mediate the behavior and response of the firm, using non-contractual mechanisms. Theory may be applied to understand the behavior of those constituencies in different political settings (Kahn, 2007) or in diverse cultures (Cherry et al, 2003).

\section{PROBLEM STATEMENT}

Decision-making in business is traditionally based on rational choice theory. This approach, based in facts quantifiable in economic terms, prioritizes the achievement of profitability and organizational effectiveness as core bottom lines. Decision-making based on rational choice relies on process models of cost/benefits, profit maximization or cost minimization. The impact on the human capital or the society is overlooked or undervalued because the assumptions of rational choice theory ignore the role of power, conflict, politics, traditions, or symbolism (Bradley et al., in Thomson, 2009), Furthermore, organizational leaders tend to ignore the rational choice principles in conditions of uncertainty, time constraints, or overwhelming data, making them prone to cross the line that separates misbehavior and legal violations (Carpenter \& Sanders, 2008). The problem is how organizational 
leaders reach full awareness of the biases in decision-making to recognize the need for adaptability to cultural changes, moral considerations and social norms (Thomson, 2009) and engage in good conversations. This study includes the proposition of an Integrative Model of Decision-making as a tool for preparation of business students in business ethics.

\section{PURPOSE STATEMENT}

The purpose of this qualitative case study is to explore the outcomes of the application of an ethical decision-making model to increase critical thinking and ethical assessment skills in business students at a public baccalaureate college in Henderson, Nevada. A proposed Integrative Model of Ethical Decision-Making will be discussed as a contribution to the body of knowledge on business ethics and the basis of instruction of business ethics at the college level.

\section{RESEARCH QUESTIONS}

The following research questions framed this study:

RQ1 What learning outcomes are achieved in the application of the Integrative Model of Ethical DecisionMaking for ethical evaluation?

RQ2 How do business students integrate "good conversations" in ethical evaluation?

\section{SIGNIFICANCE OF THE STUDY}

The significance of this study resides in illustrating how business schools play an important role in the preparation of learners in ethics and responsible citizenship. Ethics management is a core skill of effective leaders (Carpenter \& Sanders, 2008). Active learning strategies are needed in the $21^{\text {st }}$ century classroom to increase students' competencies in ethical decision-making and ethical leadership. Faculty members preparing students to undertake the challenges of competitive market environments would benefit with the incorporation of an integrative model of ethical decision making that includes good conversations.

\section{CONCEPTUAL FRAMEWORK}

Business ethics theory includes a large number of models that explain ethical behavior in business. The Integrative Model for Ethical Decision-Making proposed in this document, is an enhanced version of valuable models for ethical evaluation. This model may be used as the basis for reflection and discussion of ethical dilemmas and ethical lapses in business. The model blends critical thinking (Kubasek et al, 2003), moral reasoning (Cherry et al,, 2003), and good conversations or dialogical reasoning (Berschorner, 2006). The goal is to provide "good reasons" to avoid unethical acts and build institutions that encourage moral behaviors (Beschorner, 2006, p. 128). (See Figure 1).

A critical thinking framework for ethical decision making is incorporated to the model using Kubasek et al's (2003) six-step framework. Critical thinking is a "higher-order thinking skill" (Astleitner, 2002, p. 2) used in the evaluation of arguments, and the generation of judgmental propositions that inform individual's beliefs and actions. Analogies (Kubasek, Brennan \& Browne, 2003), logical thinking and efficient argumentation are used by critical thinkers to challenge assumptions (Duplass \& Ziedler, 2002) and tracking bias and logical fallacies in reasoning (Lundquist, 1999). However, Kubasek et al's model addresses ethics only in step 6 (What ethical norms are fundamental to the court's reasoning?).

Cherry et al's (2003) four-step model provides the framework of moral reasoning and ethical evaluation to the Integrative model. An important factor in Cherry et al's (2003) model is the identification of subjective norms that influence individuals in their decision-making process. These subjective norms and the individual's moral principles are included in the Integrative Model to influence the deontological (facts) and teleological (consequences) evaluations of ethical issues, which in turn impact individuals' attitude towards ethical issues and 
their ethical intent.

The third major element in the Integrative model is the dialogical reasoning (discourse ethics) framework. Dialogical reasoning challenges the prevailing economic rationality used by business leaders to explain the benefits or costs of a decision (Berschorner, 2006). The Integrative Ethical decision-making model proposes dialogical reasoning to integrate moral considerations to business critical thinking, allowing business people to reflect on ethical issues, and not just be guided by someone's interests, or by guidelines of the organization. The concept of "Good Conversations" (Bird, in Berschorner, 2006, p. 134) supports the model proposition. These "conversations" must occur among members of an organization, regardless of their status; and cultivated through individual and organizational learning processes. (See Figure 1).

The resulting Integrative Model for Ethical-Decision Making comprises 6 steps. Using critical thinking skills, moral reasoning and good conversations, decision-makers transition these steps toward an effective resolution. The process starts with the identification of a moral issue (Step 1) and the identification of subjective norms (Step 2). Exercising good conversations (Step 3) individuals will be able to identify alternatives (Step 4) not considered before. Using facts and consequences individuals make ethical judgments (Step 5) and engage in moral behaviors (Step 6).

\section{APPLICATION OF THE MODEL TO TEACH BUSINESS ETHICS}

This Integrative Model for Ethical Decision-Making was presented to business students in an upperdivision management course at Nevada State College in fall 2009 and used as the main resource for the evaluation of an ethical dilemma. Nevada State College is the only four-year college in Nevada providing educational access to under-served populations in the state. The business administration program is built upon a model of global competencies for leaders of the $21^{\text {st }}$ century. The upper-division course subject of this study is "Seminar in Management" offered to senior students online.

The business dilemma was presented as a scenario in the online forum, and students were asked to use the integrative ethical decision-making of good conversations to reach a decision. The Integrative Model for Ethical Decision-Making is presented in Figure 1.

Students were presented with the following scenario:

The top management team (TMT) of Cristal Clear Inc.is discussing a possible change in the technological platform of one of its plants. This decision has been urgently brought to discussion to increase the monthly productivity by approximately 20\% and respond to the upward trend in the demand. At this time, the firm has not had the ability to respond at the same rate as the demand and competitors are gaining additional share in the market. The low response by the firm is the result of an intensive use of labor over capital. The change in the technological platform will result in approximately 400 employees (out of 1200) to be laid off. The TMT needs to make a decision by next month. Union representatives have heard about these rumors and are threatening with a general strike.

Using the six steps of the ethical decision-making model proposed in the lecture of this week (Thomson, 2008), analyze the case above step by step and explain what ethical decision would you recommend?

A total of 57 responses from 25 students were exchanged in the discussion forum. All the students followed the six-step model as follows and presented their reflections in writing. Other class members engaged in the discussion and created a thread of conversations about ethics. Below is the sequence of steps of the Integrative Ethical Decision-Making model and the responses from the students. 


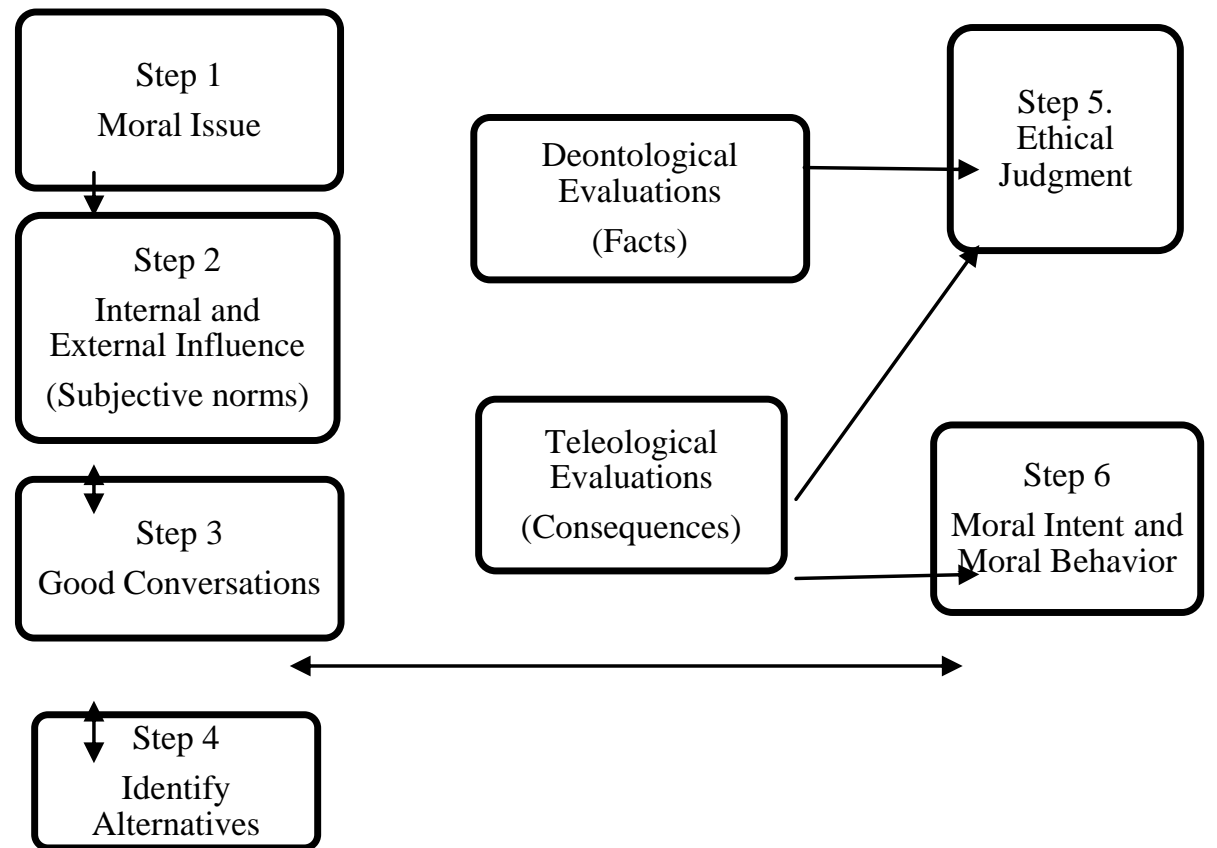

Figure 1. Components of the Integrative Ethical Decision-Making Model (Thomson, 2008)

\section{Step 1: Recognize presence of a moral issue}

Learners started by recognizing the ethical issue, related facts, and justifications (Kubasek et al., 2008). The ethical issue is the question that leads to the ethical evaluation of the business practice, while the facts provided the context of the ethical dilemma. In the identification of the issues, the community context (Cherry et al., 2003), current business practices, stakeholders' power (Beschorner, 2006), and corporate strategy (Carpenter \& Sanders, 2008) were considered. Students recognized the moral issue as "whether to sacrifice a few to save many" and pondered whether the firm should "stay in business and lay off 33\% (400) of the employees or hope for the best but, most likely have to close the firm and everyone is out of work (1200 employees)".

\section{Step 2: Identify Internal and External Influence}

Students had to identify external and internal factors or "subjective norms". External factors such as market and non-market agents are to be identified: Number of stakeholders and their power level, cultural context, industry and organizational environment (Cherry et al., 2003). Internal factors, such as characteristics of the decision-maker such as values, expectations, and cognitive development may be also assessed (Cherry et al., 2003). One of the students indicated:

In this case the external influences would be the market demand not being met by the company. The internal influences are need for faster technology driven by management teams need to show the company's profitability. Based on anomie theory (Durkheim, 1951), we argue that when organizations reconfigure in response to internal and external pressures, anomie conditions of strain and disruption may result, possibly dislodging or even deinstitutionalizing the extant normative control system (Martin, Johnson, and Cullen 2009).

\section{Step 3: Establish Good Conversations}

Using discourse ethics, it was expected that students recommended all parties to enter the dialogical process regardless of their status or power level and seek to cultivate good conversations (Bird, in Beschorner, 2006). Good conversations are characterized by openness, rationality, honesty, promise-keeping, and civility deriving in "good reasons" to engage in ethical behavior (Beschorner, 2006, 134). Students acknowledged this step 
and said:

"By means of good conversations, honest conversations, Cristal Clear Inc. may be able to "stall" the process for a longer period of time to possible come up with an alternative method other than employee termination"

"It is important to let the employees know about the problem, relay the message to everyone in the company. Because Cristal Clear Inc. is also involved with the union of workers the company must also discuss the problem and alternatives and all other issues with union representatives."

\section{Step 4: Identify Alternatives}

Students were expected to acknowledge that leaders should think beyond profit-seeking or costminimization (Beschorner, 2006). Economic rationality, transaction costs, competitive positioning, control and profit maximization are integrated to the analysis of alternatives (Argenti, 2004) complemented with a social responsibility orientation (Beschorner, 2006). The organizational mission, strategy, reputation, interests of all stakeholders, and societal benefit also inform the formulation of alternatives (Beschorner, 2006). Students were aware of these limitations and recommended the following:

"This step of thought and analysis should be considered carefully. The questions to be put to the task of evaluation are will the cost justify the means? Will the customers benefit from the production increase or id the quest just for revenue? What value does it bring to the company other than monetary? How will this decision affect the remaining employees? Are the very employees subject to layoffs our customers?"

"An alternative to just laying off 400 people would be to relocate as many of them in the company as possible and cross-train them. It does not state what these employees do but knowing the company and how it works internally is a large time saver and cost reduction in training. This "change in the technological platform" suggests that market share will become stable or increase afterwards since it is inferred that productivity to meet demand is the only reason the market share is shrinking"

\section{Step 5: Make Ethical Judgments}

Ethical judgments are a function of deontological and teleological evaluations (Cherry et al., 2003). Deontological evaluations have relevant precedence on ethical judgment because the focus is on the rightness of the act, regardless of the consequences. The ethical norms of justice, security, freedom, and efficiency (Kubasek et al., 2003) and moral standards derived from dialogical reasoning (Berschorner, 2006) are the reference for the evaluation. Teleological evaluations focus on the severity of the consequences which influence both ethical judgments and the intent to behave ethically (p. 365). Alternatives that inhibit innovation, dehumanize the work place, and create conflicts with internal and external stakeholders must be avoided (Beschorner, 2006; Paparone, 2008). Students learned about these two approaches and indicated:

"A deontological evaluation reveals that the company is making a mistake in changing platforms, since 400 workers will be losing their only employment. The workers have spent a major part of their career supporting the company, and simply releasing them is not the most ethical manner in which to address the issue."

"The teleological evaluation of reason in the case of case of Cristal Clear Inc., must take into consideration the affected employees, the union contract and its ramification, and the possible negative impact it will have on the community. It is a much broader concept than duty to the company but not absent of the company's need to compete for their market share."

\section{Step 6: Determine Moral intent and Engage in Moral Behavior}

This step follows from ethical judgment: if an individual recognizes an issue as ethically acceptable, ethical behavior will follow. In some cases it is possible that after evaluating potential consequences of unethical acts, an individual persists in behaving unethically (Cherry et al., 2003). The students were expected to suggest discourse 
ethics to engage in moral behavior. Using discourse ethics, business leaders achieve a level of self-reflection and critical questioning of "market rules, fairness, and legitimacy" (Beschorner, 2006, p. 130). Learners identified the need to continuous dialoguing, and asserted:

"This step is probably the most difficult because it encompasses all of the steps the decisions from the previous steps. Continuous evaluation and communication is necessary to see judge intent and then act out in moral behavior."

"At this step we look back at our ethical judgments made and see if our decision is morally and ethically valid. "If an individual recognizes an issue as ethically acceptable, ethical behavior will follow" (Thomson 2008) so if we choose the most ethical decision we acted as ethically as possible. Some situations, depending on your point of view, you just cannot win."

"I felt my decision from step 5 had moral intent and was as ethical as I could make it. The choice made was as beneficial to Cristal Clear Inc as possible while have as minimal an impact on the employees of the company as could be done with the facts presented."

\section{DISCUSSION}

The application of the Integrative Model of Ethical Decision-Making contributed to the discussion of ethical dilemmas and the use of critical thinking skills, moral reasoning, and dialogical approaches to problemsolving. All the students in the upper-division management course used the model systematically, explaining step by step its application to the resolution of the Crystal Clear Inc. scenario. The use of simulated scenarios engaged students in the conversation. The inclusion of the ethical model provided them with a structure and framework to organize their thinking. The outcomes of the application of the model, confirmed that students increased their skills in (1) identifying ethical issues, (2) recognizing internal and external influences, (3) using good conversations and dialogical approaches as an avenue for problem resolution, (4) generating alternative solutions to the problem informed by the dialogical exercise, (5) understanding the deontological and teleological judgments necessary to effective ethical evaluations, and (6) applying all the steps in the sequence to ensure that their moral intent results in moral behavior.

\section{APPLICATIONS TO HIGHER EDUCATION AND LEADERSHIP}

The Integrative Model of Ethical Decision-Making may be introduced to lesson plans in leadership, management and business law. Using critical thinking and dialogical reasoning (Hemming, 2000) learners are able to identify biases in their own judgments, and uphold their moral principles even in conditions of uncertainty, time constraints, or information overload. The application of the model adds a transformational leadership perspective to the study of business ethics. This model assumes that the decision-maker upholds high values and moral status, concern for followers, and interest in balancing economic and moral reasoning, using power properly. Using idealized vision, the leader becomes a role-model who embraces standards of moral conduct that followers try to emulate (Whittington, 2004).

The model of Integrative Ethical Decision-Making suggests an on-going and dynamic process of good conversations. Student and faculty themselves should be able to use good conversations in their own classroom interaction. Practice and training in dialogical reasoning will increase the openness to evaluate alternative paths to problem-solving (Braun, 2004; Ruggiero, 2004; Winn, 2004). The model may be applicable to local and global higher education institutions. Although the higher education structure and operation may differ in other countries, the stakeholders that influence decision-making are likely the same: students, parents, general public, government, employees, faculty, and administrators (American Association of State Colleges and Universities- AASCU, 2008:1).

\section{CONCLUSIONS}

The document presented arguments that support the use of critical thinking as a high-order thinking skill that assist leaders, scholars, and practitioners in higher education, in the formulation of sound reasoning. The first 
section of the document contained the background of the study, problem and purpose statement and research questions that guided the study. The conceptual framework of the Integrative Model of Ethical Decision-Making proposed by the author and the significance of the study were also included. The model integrated critical thinking, moral reasoning and dialogical approaches (good conversations). The second section of the paper included a detailed explanation of the application of the Integrative model for the instruction of business ethics in an upper-division management course.

The findings of the study suggested that business students of a public baccalaureate college in Southern Nevada understood the model of ethical decision-making, increased their awareness of ethical issues, applied deontological and teleological evaluations, and incorporated good conversations as a required step in the resolution of ethical dilemmas. The benefits of the application of the Integrative Model of Decision-Making in the curriculum of business schools may include the use of a holistic perspective of rational choice, moral reasoning and dialogical reasoning in ethics education. Using this integrative model, learners were able to combine traditional tools of costbenefit and profit maximization with good conversations to achieve an ethical decision-making outcome.

\section{AUTHOR INFORMATION}

Grace S. Thomson is an Educator and Economic consultant to the public and private sector for more than 17 years, working in capacity building and higher education in Latin America and the U.S. Her research focus integrates strategic leadership, global higher education, economic development and relationship fundraising. Grace has developed a series of taxonomies of theories of global management, organizational behavior, business ethics, finances, and relationship marketing theories.

\section{REFERENCES}

1. American Association of State Colleges and Universities (2008). Top 10 state policy issues for higher education in 2008. Policy Matters [electronic version]. Retrieved October 11, 2008, from www.aascu.org/policy matters/topten2008.htm

2. American Association of State Colleges and Universities (2006). Faculty trends and issues. Policy Matters, 3(4), 1-4. Retrieved October 10, 2008, from www.aascu.org

3. Argenti, P. (2004). Collaborating with activists: How Starbucks works with NGOs. California Management Review, 47(1), 91-115. Retrieved September 26, 2008, from Business Source complete Database.

4. Astleitner, H. (2002). Teaching critical thinking online. Journal of Instructional Psychology, 29(2), 53-77. Retrieved May 30, 2007, from InfoTrac OneFile.

5. Baron, D. P. (2006). Business and its environment (5th ed.). Upper Saddle River, NJ: Prentice-Hall.

6. Braun, N.M. (2004). Critical thinking in the business curriculum. Journal of business, 79(4), 232-236. Retrieved May 30, 2007, from ProQuest database.

7. Beschorner, T. (2006, June 15). Ethical Theory and Business Practices: The Case of Discourse Ethics. Journal of Business Ethics, 66(1), 127-139. Retrieved September 9, 2008, doi:10.1007/s10551-006-9049-x

8. $\quad$ Carpenter, M., \& Sanders, W. (2008). Strategic Management. Upper Saddle River, NJ: Pearson

9. Cherry, J., Lee, M., \& Chien, C. (2003). A cross-cultural application of a theoretical model of business ethics: Bridging the gap between theory and data. Journal of Business Ethics, 44(4), 359-376. Retrieved September 15, 2008, from Business Source Complete database.

10. Council for Higher Education Accreditation CHEA (2006). CHEA at a glance. Retrieved October 11, 2008 from http://www.chea.org/pdf/chea glance 2006.pdf

11. Hemming, H. (2000). Encouraging critical thinking: "But... what does that mean?" Journal of Education, 35(2), 173. Retrieved June 2, 2007, from ProQuest database.

12. Lundquist, R. (1999). Critical thinking and the art of making good mistakes. Teaching in Higher Education, 4(4), 523-530. Retrieved May 30, 2007, from ProQuest database.

13. Ruggiero, V. R. (2004). Beyond feelings: A guide to critical thinking (7th ed.) Boston: McGraw Hill.

14. Schulz, E., \& Tanguay, D. (2006). Merit pay in a public higher education institution: Question of impact and attitudes. Public Personnel Management, 35(1), 71-88. Retrieved October 10, 2008, from Business Source Complete database. 
15. Schwarze, S., \& Lape, H. (2001). Thinking Socratically: Critical thinking about everyday issues. Upper Saddle River, NJ: Prentice Hall.

16. Thomson, G. (2008). Taxonomy of business ethics theories. Retrieved from Selected Works of Grace Thomson

17. Thomson, G. (2008). Business Ethics in strategic management. Course materials MGT494. Nevada State College.

18. Whittington, J. (2004). Corporate executives as beleaguered rules: The leader's motive matters. Problems and Perspectives in Management, 3, 163-171. Retrieved May 16, 2007, from Business Source data base.

19. Winn, I. J. (2004, March). The high cost of uncritical teaching. Phi Delta Kappan, 85(7), 496-497. Retrieved June 2, 2007, from Pro Quest database. 